\title{
Simultaneous removal of heavy metals from aqueous solution by natural limestones
}

\author{
Ali Sdiri • Teruo Higashi
}

Received: 10 January 2012/ Accepted: 31 July 2012/Published online: 22 August 2012

(C) The Author(s) 2012. This article is published with open access at Springerlink.com

\begin{abstract}
Two natural limestone samples, collected from the Campanian-Maastrichtian limestones, Tunisia, were used as adsorbents for the removal of toxic metals in aqueous systems. The results indicated that high removal efficiency could be achieved by the present natural limestones. Among the metal ions studied, $\mathrm{Pb}^{2+}$ was the most preferably removed cation because of its high affinity to calcite surface. In binary system, the presence of $\mathrm{Cu}^{2+}$ effectively depressed the sorption of $\mathrm{Cd}^{2+}$ and $\mathrm{Zn}^{2+}$. Similarly $\mathrm{Cu}^{2+}$ strongly competed with $\mathrm{Pb}^{2+}$ to limestone surface. In ternary system, the removal further decreased, but considerable amount of $\mathrm{Pb}^{2+}$ and $\mathrm{Cu}^{2+}$ still occurred regardless of the limestone sample. The same behavior was observed in quadruple system, where the selectivity sequence was $\mathrm{Pb}^{2+}>\mathrm{Cu}^{2+}>\mathrm{Cd}^{2+}>\mathrm{Zn}^{2+}$. From these results, it was concluded that the studied limestones have the required technical specifications to be used for the removal of toxic metals from wastewaters.
\end{abstract}

Keywords Heavy metals - Limestone - Sorption · Precipitation - Competitive effects - Wastewater

\section{Introduction}

Numerous activities including metal plating, fertilizer industry, mining operations, metallurgy, battery manufacturing and textile dyeing generate a huge volume of

A. Sdiri $(\bowtie) \cdot T$. Higashi

Faculty of Life and Environmental Sciences,

University of Tsukuba, 1-1-1 Tennodai, Tsukuba,

Ibaraki 305-8572, Japan

e-mail: alisdiri@yahoo.fr

T. Higashi

e-mail: Labsoils@sakura.cc.tsukuba.ac.jp wastewater contaminated with various metals (Eloussaief and Benzina 2010; Eloussaief et al. 2011, 2012; Sdiri et al. 2012a). These metals constitute a real threat for the environment because of their adverse effects on living organisms and water quality (Barhoumi et al. 2009; Messaoudi et al. 2009). Therefore, the levels of such pollutants in water body have to be reduced to the minimum. The use of natural sorbent for removing various metals from wastewater has been found to be an effective alternative. Especially, the use of natural limestones as cheap medium for toxic metals removal has been investigated by multiple researchers (Aziz et al. 2001; Sanchez and Ayuso 2002; Godelitsas et al. 2003; Prieto et al. 2003; Komnitsas et al. 2004; Cave and Talens-Alesson 2005; Rouff et al. 2006; Aziz et al. 2008; Sdiri et al. 2012b), pointing out that limestones could be an efficient natural geological materials for the treatment of heavy metals in contaminated water. Martins et al. (2004) mentioned that zinc sorption was favored as water hardness (i.e., $\mathrm{Ca}^{2+}$ ) increased. Al-Degs et al. (2006) also studied the process that governs the interaction between $\mathrm{Pb}^{2+}$ and $\mathrm{Zn}^{2+}$ and calcite (eventually calcium). They mentioned that based on some theoretical assumptions, the removal of lead should be preferred over zinc. The released calcium in the solution was in tight relationship with the removed metal (i.e., lead and zinc). These may serve as a guide when studying the interactive behavior of calcium and metals. However, most of the reported metal removal efficiency of limestone dealt with single-element system. Desired intensive remediation is usually concerned with contaminated water that contains more than one heavy metal. To date, no attempt has been made to study the interactive mechanisms involved in metal-carbonates interactions in mixed systems. Therefore, the present study provided an attempt to (1) examine the adsorption behavior of several divalent metals onto natural limestones in single 
and multi-element systems, (2) to determine the mechanisms involved in the removal processes, (3) to study the competitive sorption of $\mathrm{Pb}^{2+}, \mathrm{Cd}^{2+}, \mathrm{Cu}^{2+}$ and $\mathrm{Zn}^{2+}$ in single, binary, ternary and quadruple systems and (4) to discuss the feasibility of using natural limestones from Tunisia in wastewater cleanup.

\section{Materials and methods}

\section{Limestones samples used}

Two limestone samples ( $\mathrm{S}$ and $\mathrm{Z}$ ) of the CampanianMaastrichtian Abiod formation were collected from the outcroppings in the areas of Gafsa (southern Tunisia, Z samples) and Bizerte (northern Tunisia, S sample) where the geological particularities of the material allow its use in a wide range of industrial and environmental applications (Bouaziz et al. 2007; Aloui and Chaabani 2007). The collected limestone blocks were crushed, sieved and a grain size of less than $210 \mu \mathrm{m}$ was used for batch sorption.

All of the chemical reagents were of analytical grade supplied by Wako Pure Chemical Industries, Ltd. (Japan). Ultrapure water (UPW) produced with a Milli-Q system (Millipore Corp., France) was used throughout the experiments. Working standards were prepared by the dilution of the stock solution $(1,000 \mathrm{mg} / \mathrm{L})$, prepared by dissolving proper amount of copper, cadmium, lead and zinc chloride in $100 \mathrm{~mL}$ of hydrochloric acid $(0.1 \mathrm{~mol} / \mathrm{L})$. Solutions of $0.1 \mathrm{M} \mathrm{HCl}$ and $0.1 \mathrm{M} \mathrm{NaOH}$ were used for $\mathrm{pH}$ adjustment.

\section{Batch sorption}

Batch sorption, a technique commonly used to obtain data on the removal efficiency of a given sorbent under static conditions, was selected as an appropriate technique in the current study. Polypropylene tubes containing $20 \mathrm{~mL}$ of metal solution and $3 \mathrm{~g} / \mathrm{L}$ of limestone powder from the $<210 \mu \mathrm{m}$-sized samples ( $\mathrm{S}$ or $\mathrm{Z}$ ) were shaken at $200 \mathrm{rpm}$ at $25^{\circ} \mathrm{C}$ for $60 \mathrm{~min}$ to reach equilibrium. In single, binary and multi-element systems, $10 \mathrm{mg} / \mathrm{L}$ of each metal was used as an initial concentration to achieve similar concentration for all systems (molar concentration: $[\mathrm{Pb}]=$ $4.82 \times 10^{-5} \mathrm{~mol} / \mathrm{L}, \quad[\mathrm{Cd}]=8.89 \times 10^{-5} \mathrm{~mol} / \mathrm{L},[\mathrm{Cu}]=$ $1.57 \times 10^{-4} \mathrm{~mol} / \mathrm{L}$ and $[\mathrm{Zn}]=1.52 \times 10^{-4} \mathrm{~mol} / \mathrm{L}$ ). For instance, in quadruple system, $5 \mathrm{~mL}$ of each metal stock solution $(1,000 \mathrm{mg} / \mathrm{L})$ were introduced in $500 \mathrm{~mL}$ volumetric flask and then diluted with UPW to obtain an initial concentration of $10 \mathrm{mg} / \mathrm{L}$ for each metal. The initial $\mathrm{pH}$ of the solution was adjusted to 6 with $0.1 \mathrm{M} \mathrm{HCl}$ and $0.1 \mathrm{M}$ $\mathrm{NaOH}$ prior to mixing with limestone powder (Sdiri et al. 2012b). After shaking, $10 \mathrm{~mL}$ of supernatant were withdrawn and filtered through a $0.2 \mu \mathrm{m}$ syringe-driven filter (Millex-LG, PTFE, Millipore Corp., Ireland). After the reaction, the sample solutions were stored at $4{ }^{\circ} \mathrm{C}$ until analysis for $\mathrm{Pb}^{2+}, \mathrm{Cd}^{2+}, \mathrm{Cu}^{2+}$ and $\mathrm{Zn}^{2+}$ with an ICP-AES instrument, Optima 7300 DV series (PerkinElmer Inc., Tokyo, Japan). The amount of a metal removed from the solution was calculated as the difference between initial and final concentrations. The same experimental conditions were maintained for mixed systems (i.e., binary, ternary and quadruple mixtures). All experiments were run in triplicate.

\section{Results and discussion}

\section{Characterization of limestone samples}

Chemical composition was determined by subjecting the pressed limestone samples to an electron microprobe equipped with an X-ray dispersive spectrometer (JXA8621 Superprobe; JEOL, Tokyo, Japan). It showed that the limestone samples collected from the southern area (i.e., Z sample) was characterized by its high purity, while the northern $\mathrm{S}$ sample contained more than $16.856 \% \mathrm{SiO}_{2}$ and minor amounts of iron and aluminum oxides (Table 1).

Mineralogical analysis was carried out for powder samples with an X-ray diffractometer (RAD-X; Rigaku Intl. Corp., Tokyo, Japan). XRD patterns of the studied limestone samples showed the presence of characteristic peaks of calcite (Sdiri et al. 2010). In the northern S sample, the additional peak prevailing at $3.34 \AA$ showed the presence of quartz (Fig. 1). The specific surface areas, determined using the $\mathrm{N}_{2}$-sorption method (SA 3100, Beckman Coulter, USA), were 6.25 and $1.03 \mathrm{~m}^{2} / \mathrm{g}$ for $\mathrm{S}$ and $\mathrm{Z}$ samples, respectively.

The studied limestone samples were also characterized by FTIR spectrophotometer (FT-720; Horiba, Ltd., Tokyo, Japan) over a range of 4,000-650 $\mathrm{cm}^{-1}$ at room temperature. The obtained spectra showed broad bands near 1,400, 875 and $711 \mathrm{~cm}^{-1}$, characteristic of calcite. The maximum absorption recorded at $1,095.37,1,064.51$ and $985.447 \mathrm{~cm}^{-1}$ was attributed to the asymmetric stretching of $\mathrm{Si}-\mathrm{O}$ (Fig. 2). The presence of high amount of silica may effectively enhance the adsorptive capacity of $S$ sample when compared with the pure Z limestone (Sdiri et al. 2010).
Table 1 Chemical composition of the studied limestone samples (by weight \%)

$N D$ not detected

\begin{tabular}{lllllllllll}
\hline Sample & $\mathrm{CaCO}_{3}$ & $\mathrm{SiO}_{2}$ & $\mathrm{Al}_{2} \mathrm{O}_{3}$ & $\mathrm{Fe}_{2} \mathrm{O}_{3}$ & $\mathrm{~K}_{2} \mathrm{O}$ & $\mathrm{MnO}$ & $\mathrm{SO}_{3}$ & $\mathrm{SrO}$ & $\mathrm{TiO}_{2}$ & Total \\
\hline $\mathrm{S}$ & 76.671 & 16.856 & 3.003 & 2.056 & 0.831 & 0.117 & $\mathrm{ND}$ & 0.228 & 0.238 & 100 \\
$\mathrm{Z}$ & 99.609 & 0.391 & $\mathrm{ND}$ & $\mathrm{ND}$ & $\mathrm{ND}$ & $\mathrm{ND}$ & $\mathrm{ND}$ & $\mathrm{ND}$ & $\mathrm{ND}$ & 100 \\
\hline
\end{tabular}


Sorption experiments of heavy metals by a batch method

\section{Sorption in single-element system}

Sorption experiments of the selected metal cations were performed by shaking the known amount of natural limestone powder with metal solution at room temperature $\left(25^{\circ} \mathrm{C}\right)$. The initial concentration of metal was kept at

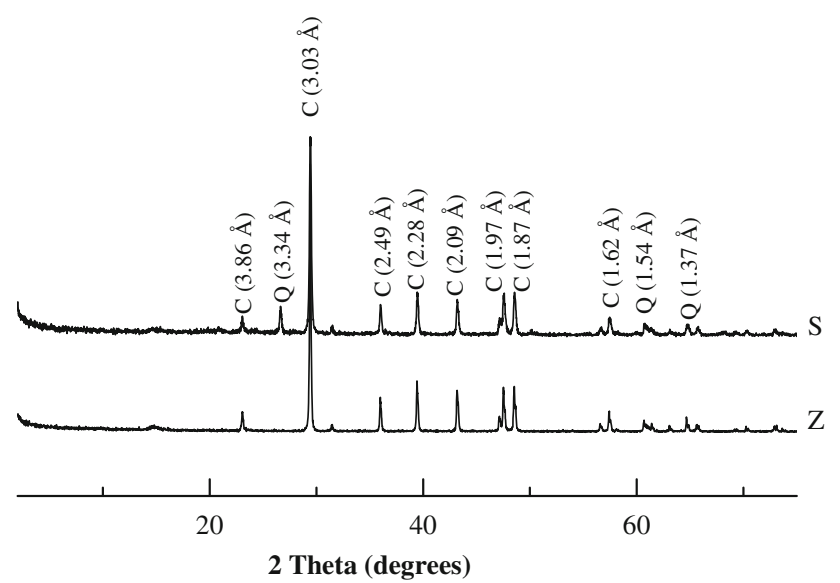

Fig. 1 XRD patterns of the studied limestone samples
$10 \mathrm{mg} / \mathrm{L}$ (i.e., $[\mathrm{Pb}]=4.82 \times 10^{-5} \mathrm{~mol} / \mathrm{L},[\mathrm{Cd}]=8.89 \times$ $10^{-5} \mathrm{~mol} / \mathrm{L},[\mathrm{Cu}]=1.57 \times 10^{-4} \mathrm{~mol} / \mathrm{L}$ and $[\mathrm{Zn}]=1.52 \times$ $10^{-4} \mathrm{~mol} / \mathrm{L}$ ). The dose of limestone sample was $3 \mathrm{~g} / \mathrm{L}$ and the heavy metal solution of $\mathrm{pH} 6$ was introduced. Preliminary results showed that $\mathrm{Pb}^{2+}$ was totally removed under the experimental conditions of this study (Sdiri et al. 2011). This indicates that the removal of lead ions by limestone is predominantly governed by the precipitation of lead carbonate (Sanchez and Ayuso 2002; Davis et al. 2006; Karageorgiou et al. 2007). The lower precipitation $\mathrm{pH}$ of $\mathrm{PbCO}_{3}$ (pH 5.3) and the solubility product constant $\left(K_{\text {sp }}=7.4 \times 10^{-14}\right.$ at $\left.25^{\circ} \mathrm{C}\right)$ would explain this phenomenon. Above that $\mathrm{pH}$ value, $\mathrm{PbCO}_{3}$ solid phase should be formed, leading to high sorption capacity, since equilibrium $\mathrm{pH}$ increased to 7.7 after the addition of limestone. Several previous works confirmed that carbonate precipitation was especially effective for the removal of lead (Godelitsas et al. 2003; Rouff et al. 2006). That is why, subsequent experiments in single-element systems focused only on $\mathrm{Cd}^{2+}, \mathrm{Cu}^{2+}$ and $\mathrm{Zn}^{2+}$ sorption. In binary and multi-component systems, $\mathrm{Pb}^{2+}$ was re-introduced because of its decreased removal percentage under competitive conditions.

While the theoretical precipitation of $\mathrm{CdCO}_{3}\left(K_{\mathrm{sp}}=\right.$ $1 \times 10^{-12}$ at $25^{\circ} \mathrm{C}$ ) begins at $\mathrm{pH} 8.5$, an initial
Fig. 2 FTIR spectra of the studied limestone samples
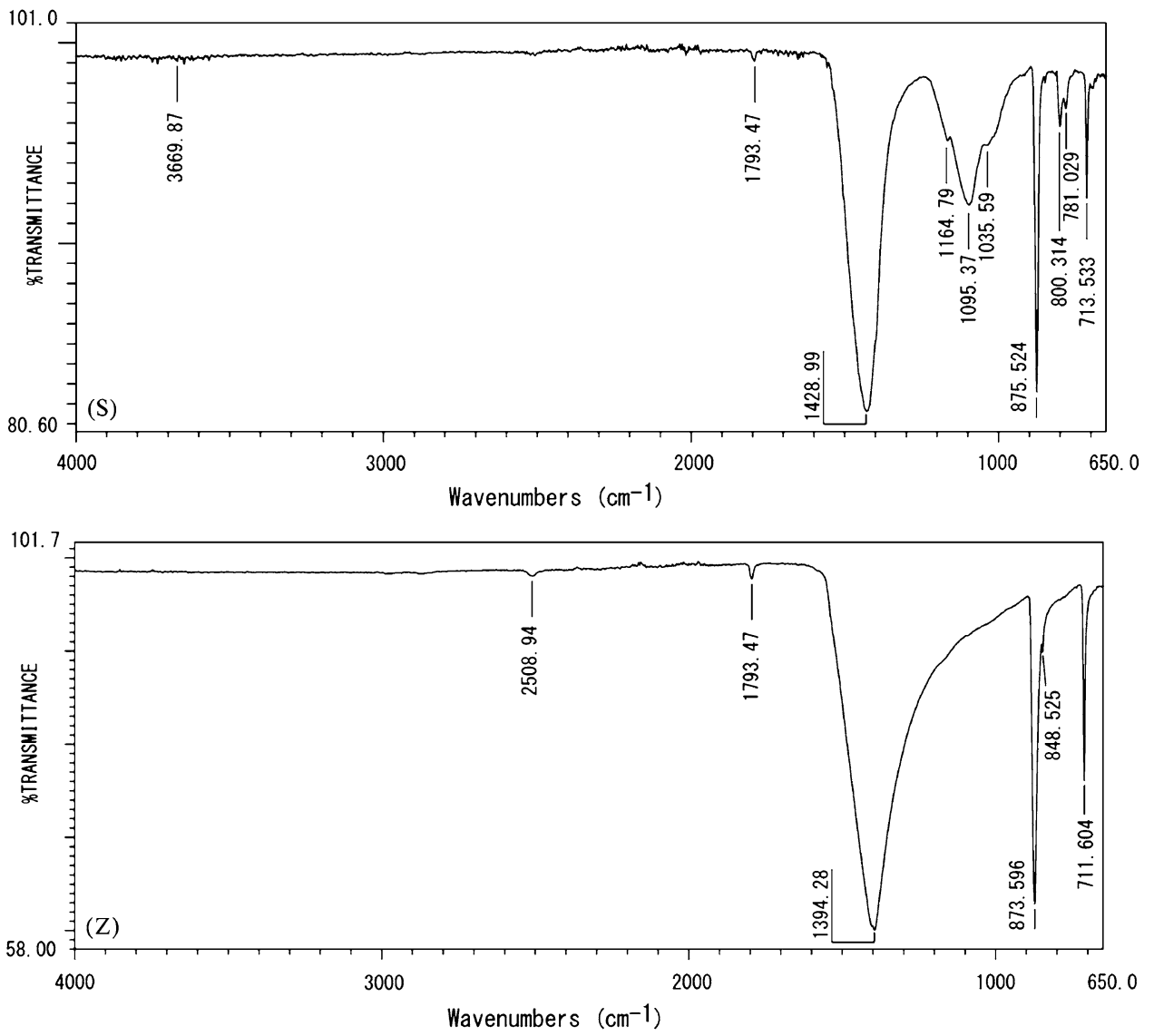
chemisorption step may also serve as a removal mechanism (Pickering 1983). Our results clearly showed that higher removal efficiency from the lower grade limestone sample (S) was probably related to its higher specific surface area, combined with elevated concentrations of silica and other impurities, as indicated earlier in this paper. To get more insights on the removal mechanisms, the dissolved calcium during the present sorption study was measured and compared in the case of $\mathrm{Pb}$ and $\mathrm{Cd}$ removal by limestone. It was confirmed that the presence of lead favored calcite dissolution, while cadmium inhibited calcium carbonate dissolution to some extent. Calcium concentration exceeded $40 \mathrm{mg} / \mathrm{L}$ in the case of lead removal, but less than $25 \mathrm{mg} / \mathrm{L}$ during the removal of cadmium regardless of the limestone sample. Similar findings were reported by Alkattan et al. (2002), Martin-Garin et al. (2003) and Cubillas et al. (2005) while studying the effect of metal sorption on calcite dissolution.

The sorption of single metal $\left(\mathrm{Cd}^{2+}, \mathrm{Cu}^{2+}\right.$ and $\left.\mathrm{Zn}^{2+}\right)$ onto limestone is shown in Fig. 3. The overall removal percentage for $\mathrm{Cd}^{2+}$ was 95.00 and $14.68 \%$ for $\mathrm{S}$ and $\mathrm{Z}$ sample, respectively. Although it has been reported that cadmium is the metal cation which replaces $\mathrm{Ca}^{2+}$ more easily, due to the similarity of their ionic radii (Sanchez and Ayuso 2002; Al-Degs et al. 2006), it was observed that the exchange mechanism for cadmium occurs to lower extent. Moreover, it could be presumed that cadmium could exert an inhibitory effect on calcite dissolution (Martin-Garin et al. 2003), resulting in the reduction of the
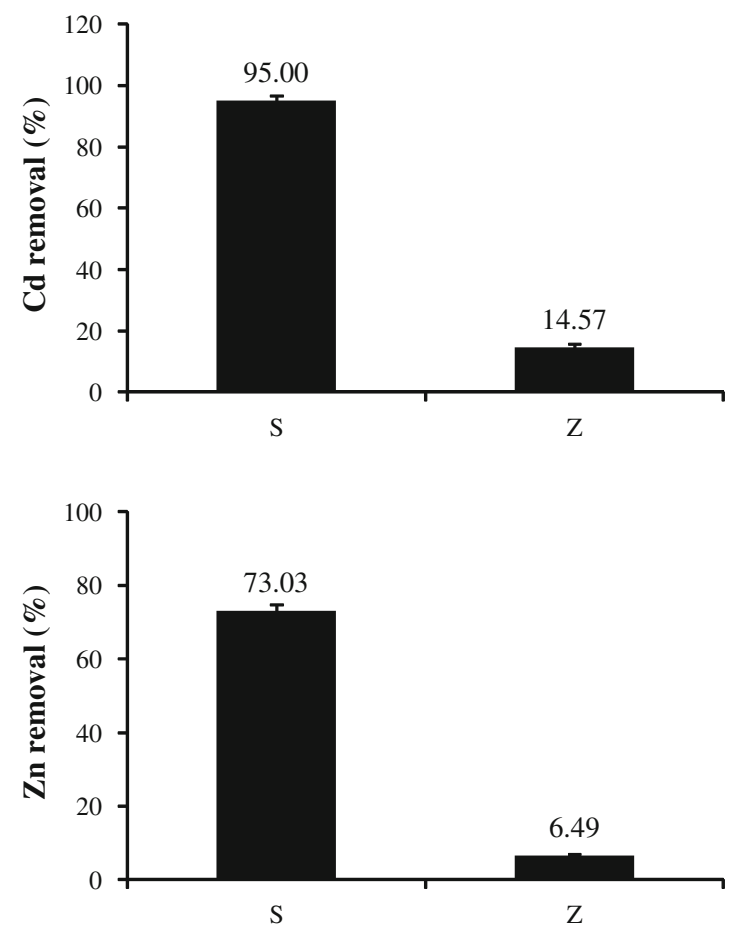

Fig. 3 Sorption of $\mathrm{Cu}, \mathrm{Cd}$ and $\mathrm{Zn}$ in single system available site for metal sorption. Similar findings were reported by Alkattan et al. (2002) and Cubillas et al. (2005) while studying the effect of metal sorption on calcite dissolution. These results may explain the lowest removal capacity of the purest limestone ( $\mathrm{Z}$ sample). The efficiency of copper removal varied from 37.68 to $91 \%$, indicating that pure limestone had better affinity to this element in comparison with cadmium. The high removal percentage of copper was also favored by the presence of bicarbonate ions in the aqueous medium leading to the precipitation as copper carbonates. The precipitation $\mathrm{pH}$ of $\mathrm{CuCO}_{3}(\mathrm{pH} 6)$ was lower than the final $\mathrm{pH}(\mathrm{pH}$ 7.7) indicating that the precipitation mechanism governed most of copper removal. As for zinc, less than $20 \%$ removal was achieved by the pure $\mathrm{Z}$ sample that is much lower than the removal percentage (73\%) by S sample (Fig. 3). According to Pickering (1983) and Sanchez and Ayuso (2002), the available sites that bind preferably to $\mathrm{Zn}^{2+}$ represent less than $10 \%$ of the total active sites. Our results showed that the higher removal efficiency, completed by the lower grade limestone sample (S), was probably related to its higher specific surface area combined with the high amounts of silica and other impurities, as discussed earlier (Fig. 3).

\section{Sorption in binary system}

Sorption experiments of heavy metals were also studied in mixed systems by shaking $60 \mathrm{mg}$ of natural limestone $(<210 \mu \mathrm{m}$-sized powder) with $20 \mathrm{~mL}$ of metal solution at

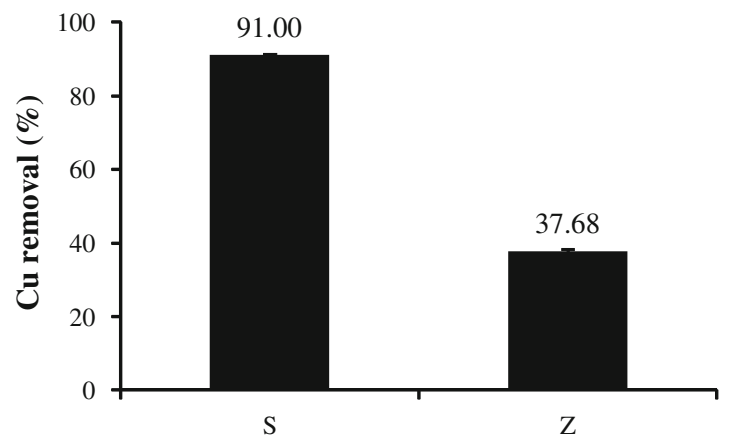



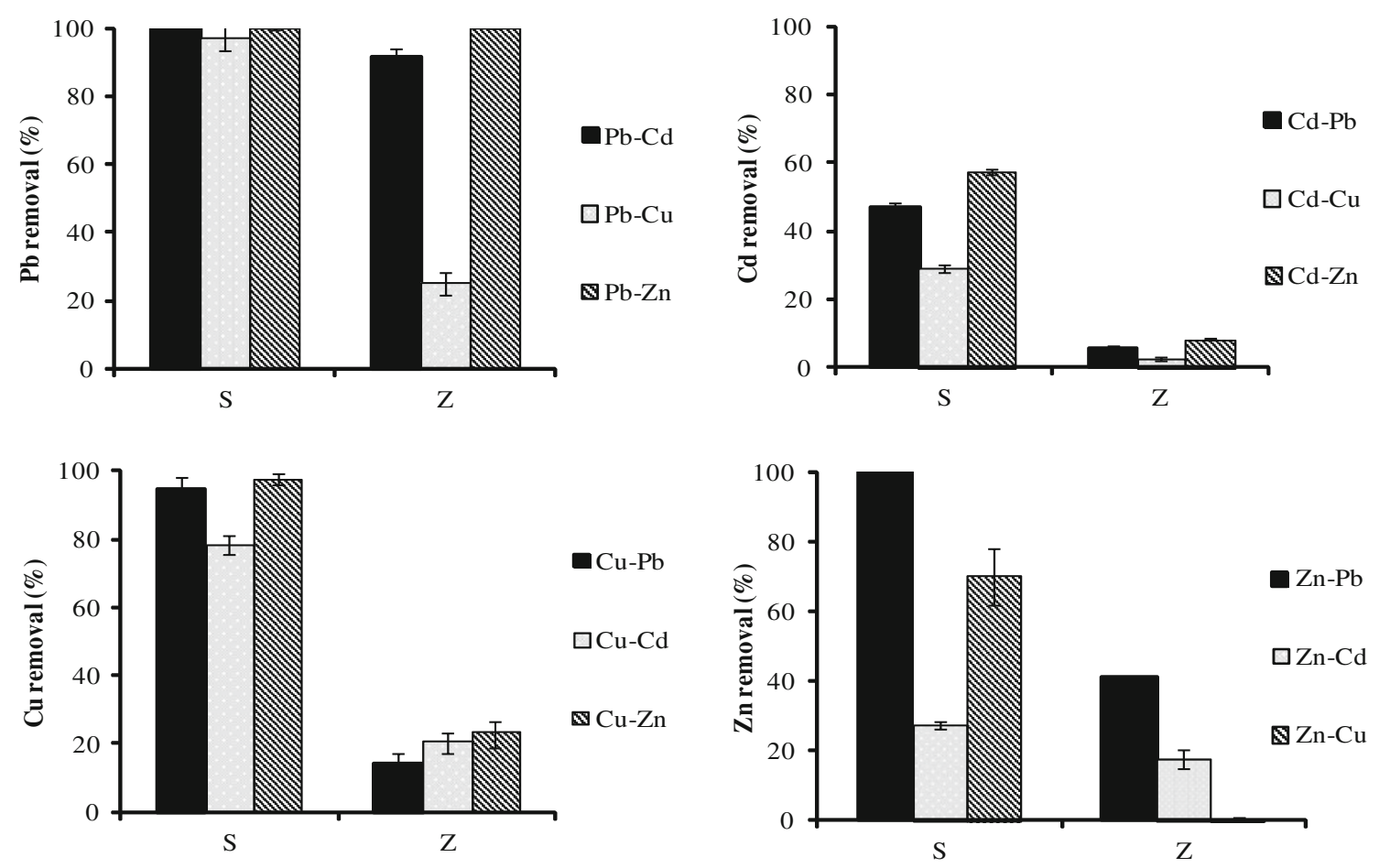

Fig. 4 Sorption of $\mathrm{Pb}^{2+}, \mathrm{Cd}^{2+}, \mathrm{Cu}^{2+}$ and $\mathrm{Zn}^{2+}$ in binary systems

room temperature $\left(25^{\circ} \mathrm{C}\right)$ for $60 \mathrm{~min}$. The initial concentration of metal was fixed at $10 \mathrm{mg} / \mathrm{L}$ for each metal and $\mathrm{pH}$ 6. Figure 4 shows the removal percentage of $\mathrm{Pb}^{2+}$, $\mathrm{Cd}^{2+}, \mathrm{Cu}^{2+}$ and $\mathrm{Zn}^{2+}$ sorbed onto $\mathrm{S}$ and $\mathrm{Z}$ limestone samples at $\mathrm{pH} 6$ for all possible metal combinations in binary systems. The results showed that $\mathrm{S}$ limestone sample showed higher removal efficiency regardless of the metal to be removed. Generally, the removal rate by $\mathrm{S}$ limestone sample was much higher than that achieved by $\mathrm{Z}$ sample, suggesting that the enhanced removal capacity correlated with the presence of impurities. In $\mathrm{Pb}-\mathrm{Cd}$ systems, more than $91.5 \%$ removal of $\mathrm{Pb}^{2+}$ was observed in all cases. The removal percentages in the presence of $\mathrm{Cd}^{2+}$ were $99.67 \%$ for $\mathrm{S}$ sample and $91.42 \%$ for $\mathrm{Z}$ sample. The removal efficiency of $\mathrm{Cd}^{2+}$ decreased substantially in the presence of $\mathrm{Pb}^{2+}$ compared with single-element system (Figs. 3, 4). Therefore, $\mathrm{Pb}^{2+}$ strongly depressed $\mathrm{Cd}^{2+}$ sorption onto limestone samples, showing an inhibitory effect on $\mathrm{Cd}$ removal [defined as IE $(\%)=\left(\mathrm{Cd}_{(\mathrm{Cd})}-\right.$ $\left.\mathrm{Cd}_{(\mathrm{Pb}-\mathrm{Cd})}\right) / \mathrm{Cd}_{(\mathrm{Cd})}$ where $\mathrm{Cd}_{(\mathrm{Cd})}, \mathrm{Cd}_{(\mathrm{Pb}-\mathrm{Cd})}$ are $\mathrm{Cd}$ removal percentage in single and binary system, respectively] of $50.82 \%$ and $60.60 \%$ for $\mathrm{S}$ and $\mathrm{Z}$ samples, respectively. This was further confirmed by the removal efficiencies of $\mathrm{Cd}^{2+}$, which decreased to 46.72 and $5.74 \%$ for $\mathrm{S}$ and $\mathrm{Z}$ limestone samples, respectively. Inversely, the inhibitory effect of $\mathrm{Cd}^{2+}$ on $\mathrm{Pb}^{2+}$ removal occurred to much lower extent because of higher selectivity for $\mathrm{Pb}^{2+}$. The interactive behavior of $\mathrm{Pb}-\mathrm{Cu}$ system showed that $\mathrm{Pb}^{2+}$ had somewhat higher affinity to limestone than $\mathrm{Cu}^{2+}$. Similar results were reported by Xue et al. (2009), who studied competitive adsorption of heavy metals onto basic oxygen furnace slag. It was found that the presence of $\mathrm{Pb}^{2+}$ strongly prevented the removal of $\mathrm{Cu}^{2+}$ by the limestone sample (Z) with an IE of $62.52 \%$, but not $\mathrm{S}$ sample (Table 3). Interestingly, $\mathrm{Pb}^{2+}$ slightly enhanced the removal of $\mathrm{Cu}^{2+}$ with $\mathrm{S}$ limestone sample probably due to the presence of high affinity sites that adsorb both $\mathrm{Pb}^{2+}$ and $\mathrm{Cu}^{2+}$ under the conditions of our experiments. This behavior was confirmed by the poor effect of $\mathrm{Cu}^{2+}$ on $\mathrm{Pb}^{2+}$ removal, though higher than those of $\mathrm{Cd}^{2+}$ and $\mathrm{Zn}^{2+}$. For $\mathrm{Z}$ limestone sample, the inhibitory effect of copper over lead exceeded $50 \% . \mathrm{Cu}^{2+}$ also showed strong inhibitory effects over $\mathrm{Cd}^{2+}$ and $\mathrm{Zn}^{2+}$. This was expected since copper was predominantly sorbed by all the studied samples over cadmium and zinc because of its higher relative binding strength and lower ionization potential (Table 2). As for $\mathrm{Cd}-\mathrm{Zn}$ system, it was observed that $\mathrm{Cd}^{2+}$ strongly prevented the removal of $\mathrm{Zn}^{2+}$ cations. Similarly, $\mathrm{Zn}^{2+}$ inhibited the removal of $\mathrm{Cd}^{2+}$ to the same order of magnitude, though slightly lower. Moreover, in $\mathrm{Pb}-\mathrm{Zn}$ system, the coexistence of these two metals favored the removal of $\mathrm{Zn}^{2+}$, but not $\mathrm{Pb}^{2+}$. This meant that there was simultaneous binding of both metals with the same binding sites. Hence, it is plausible to account for an uncompetitive sorption or 
Table 2 Physical characteristics of the studied cations (Kinraide and Yermiyahu 2007)

\begin{tabular}{llllllll}
\hline Cation & RBS & PE & IR & IP & HR & $-\log K_{\mathrm{H}_{2} \mathrm{O}, \mathrm{M}}$ & $\mathrm{HI}$ \\
\hline $\mathrm{Ca}^{2+}$ & 1.44 & 1 & 0.99 & 6.11 & 4.12 & 12.7 & 0.181 \\
$\mathrm{Cd}^{2+}$ & 2.15 & 1.69 & 0.97 & 8.99 & 4.26 & 10.1 & 0.081 \\
$\mathrm{Cu}^{2+}$ & 2.66 & 1.9 & 0.73 & 7.73 & 4.19 & 7.5 & 0.104 \\
$\mathrm{~Pb}^{2+}$ & 2.68 & 2.33 & 1.19 & 7.42 & 4.01 & 7.6 & 0.131 \\
$\mathrm{Zn}^{2+}$ & 2.2 & 1.65 & 0.74 & 9.39 & 4.3 & 9 & 0.115 \\
\hline
\end{tabular}

$R B S$ relative binding strengths, $P E$ Pauling electronegativity, $I R$ ionic radius, $I P$ ionization potential, $H R$ hydrated radius, $-\log K_{\mathrm{H}_{2} \mathrm{O}, \mathrm{M}} \log$ of the first hydrolysis constant, $H I$ hardness index

Table 3 Inhibitory effect (\%) of a competing metal on other metals sorption onto limestones

\begin{tabular}{llllll}
\hline Sample & Inhibitor & \multicolumn{2}{l}{ Inhibited } & & \\
\cline { 3 - 6 } & & $\mathrm{Pb}^{2+}$ & $\mathrm{Cd}^{2+}$ & $\mathrm{Cu}^{2+}$ & $\mathrm{Zn}^{2+}$ \\
\hline $\mathrm{S}$ & $\mathrm{Pb}^{2+}$ & - & 0.330 & 2.970 & 0.001 \\
& $\mathrm{Cd}^{2+}$ & 50.822 & - & 69.441 & 45.768 \\
& $\mathrm{Cu}^{2+}$ & -3.991 & 13.934 & - & -7.187 \\
& $\mathrm{Zn}^{2+}$ & -36.933 & 62.625 & 4.217 & - \\
$\mathrm{Z}$ & $\mathrm{Pb}^{2+}$ & - & 8.582 & 75.002 & 0.003 \\
& $\mathrm{Cd}^{2+}$ & 60.603 & - & 81.949 & 41.935 \\
& $\mathrm{Cu}^{2+}$ & 62.520 & 45.806 & - & 39.039 \\
& $\mathrm{Zn}^{2+}$ & -531.741 & - & 100 & - \\
\hline
\end{tabular}

even a favorable sorption for $\mathrm{Zn}^{2+}$ in the presence of $\mathrm{Pb}^{2+}$, despite their different properties (Table 2). The increased removal of zinc in the presence of lead would suggest a coprecipitation mechanism that enhances the removal of zinc. However, other mechanisms (i.e., sorption and precipitation) would contribute to the removal efficiency. The sorption of $\mathrm{Zn}$ cations on $\mathrm{Pb}(\mathrm{OH})_{2}$ is not to be excluded, but it contributed to a very low extent because of the fact that the precipitation as lead hydroxide started at $\mathrm{pH}$ 7.6, that was bit lower than the final $\mathrm{pH}$ (of 7.7). This was further confirmed by the negative IE exerted by $\mathrm{Pb}^{2+}$ on $\mathrm{Zn}^{2+}$ (Table 3).

\section{Sorption in ternary system}

Competitive sorption experiments were also performed by simultaneous removal of three metals under the same experimental conditions described earlier. That is, sorption experiments performed by shaking $60 \mathrm{mg}$ of natural limestone $(<210 \mu \mathrm{m}$-sized powder) with $20 \mathrm{~mL}$ of metal solution at room temperature $\left(25^{\circ} \mathrm{C}\right)$ for $60 \mathrm{~min}$. The initial concentration of metal was fixed at $10 \mathrm{mg} / \mathrm{L}$ for each metal and an initial $\mathrm{pH}$ of 6 . The results of removal percentages are shown in Fig. 5, where it was indicated that $\mathrm{S}$ limestone sample removed the highest amounts of heavy metal, while $\mathrm{Z}$ sample retained the lowest amounts regardless of the removed cation and the studied mixture. Moreover, the affinity of the studied metal cations for limestone sample followed the sequence of $\mathrm{Pb}^{2+}>$ $\mathrm{Cu}^{2+}>\mathrm{Zn}^{2+} \approx \mathrm{Cd}^{2+}$. Similar sequence has been reported for the competitive adsorption of several metals onto basic oxygen slag (Xue et al. 2009), who found a sequence of $\mathrm{Pb}^{2+}>\mathrm{Cu}^{2+}>\mathrm{Zn}^{2+}>\mathrm{Cd}^{2+}$, confirming that $\mathrm{Pb}^{2+}$ had the highest affinity to the surface of carbonate than others. Nevertheless, according to the above-mentioned work, the sequence changes considerably in single-element system that was not the case for the present study. Comparing the data obtained for lead, cadmium, copper and zinc, strong relationship between metal removal percentage and its first hydrolysis constant was observed (Kinraide and Yermiyahu 2007; Appel et al. 2008; Zhu et al. 2010). Lead removal capacity of $\mathrm{S}$ limestone sample clearly increased from $78.66 \%$ in $\mathrm{Pb}-\mathrm{Cd}-\mathrm{Cu}$ mixture to $90.75 \%$ in $\mathrm{Pb}-\mathrm{Cd}-$ $\mathrm{Zn}$ system. Similar results were obtained for $\mathrm{Z}$ sample, with an increasing percentage of $61.93 \%$ (Table 4). In $\mathrm{Pb}-\mathrm{Cu}-\mathrm{Zn}$ system, the removed amounts of lead were higher than those observed in $\mathrm{Pb}-\mathrm{Cd}-\mathrm{Cu}$ system, but much lower than those recorded in $\mathrm{Pb}-\mathrm{Cd}-\mathrm{Zn}$ mixture. Since copper suppressed the removal of $\mathrm{Pb}^{2+}$, it was expected that lead removal would be lower in the presence of $\mathrm{Cu}^{2+}$. In the presence of $\mathrm{Zn}^{2+}$, the removal of lead jumped to more than $75 \%$ for all samples in $\mathrm{Pb}-\mathrm{Cd}-\mathrm{Zn}$ system, but decreased in $\mathrm{Pb}-\mathrm{Cu}-\mathrm{Zn}$ mixture. These results indicate the antagonistic effect of $\mathrm{Zn}^{2+}$ and $\mathrm{Cu}^{2+}$. Such explanation also applies for cadmium removal by the studied limestone samples. As for copper, the removal efficiency of $Z$ sample in $\mathrm{Pb}-\mathrm{Cd}-\mathrm{Cu}$ system has readily increased in $\mathrm{Pb}-\mathrm{Cu}-\mathrm{Zn}$ and $\mathrm{Cd}-\mathrm{Cu}-\mathrm{Zn}$ (Table 4). Finally, it is worth noting that zinc removal remained roughly unchangeable in all cases probably because of its low electronegativity combined with high ionization potential (Table 2).

\section{Sorption in quadruple system}

Mixed metal sorption of $\mathrm{Pb}^{2+}, \mathrm{Cd}^{2+}, \mathrm{Cu}^{2+}$ and $\mathrm{Zn}^{2+}$ ions by natural limestone samples was also investigated to establish the effect of the presence of three metal ions on the removal of each one of them in equal concentration of $10 \mathrm{mg} / \mathrm{L}$. Figure 6 revealed that the studied limestone samples had high affinity to $\mathrm{Pb}^{2+}$, leading to the highest removal percentages. Lead removal efficiency was 75.02 and $6.57 \%$ for $\mathrm{S}$ and $\mathrm{Z}$ samples, respectively. The sorption capacity of $\mathrm{Cu}^{2+}$ was about $59.5 \%$ for S sample, but only $7.05 \%$ for $\mathrm{Z}$ sample. This also indicated the high affinity to $\mathrm{Cu}^{2+}$, but somewhat lower than $\mathrm{Pb}^{2+}$. As for $\mathrm{Cd}^{2+}$ and $\mathrm{Zn}^{2+}$, low removal percentage was achieved by $\mathrm{S}$ limestone sample, but $\mathrm{Z}$ sample, considered as pure limestone samples, was not able to remove measurable amounts of $\mathrm{Cd}^{2+}$ and $\mathrm{Zn}^{2+}$. It could be assumed that the studied limestones 

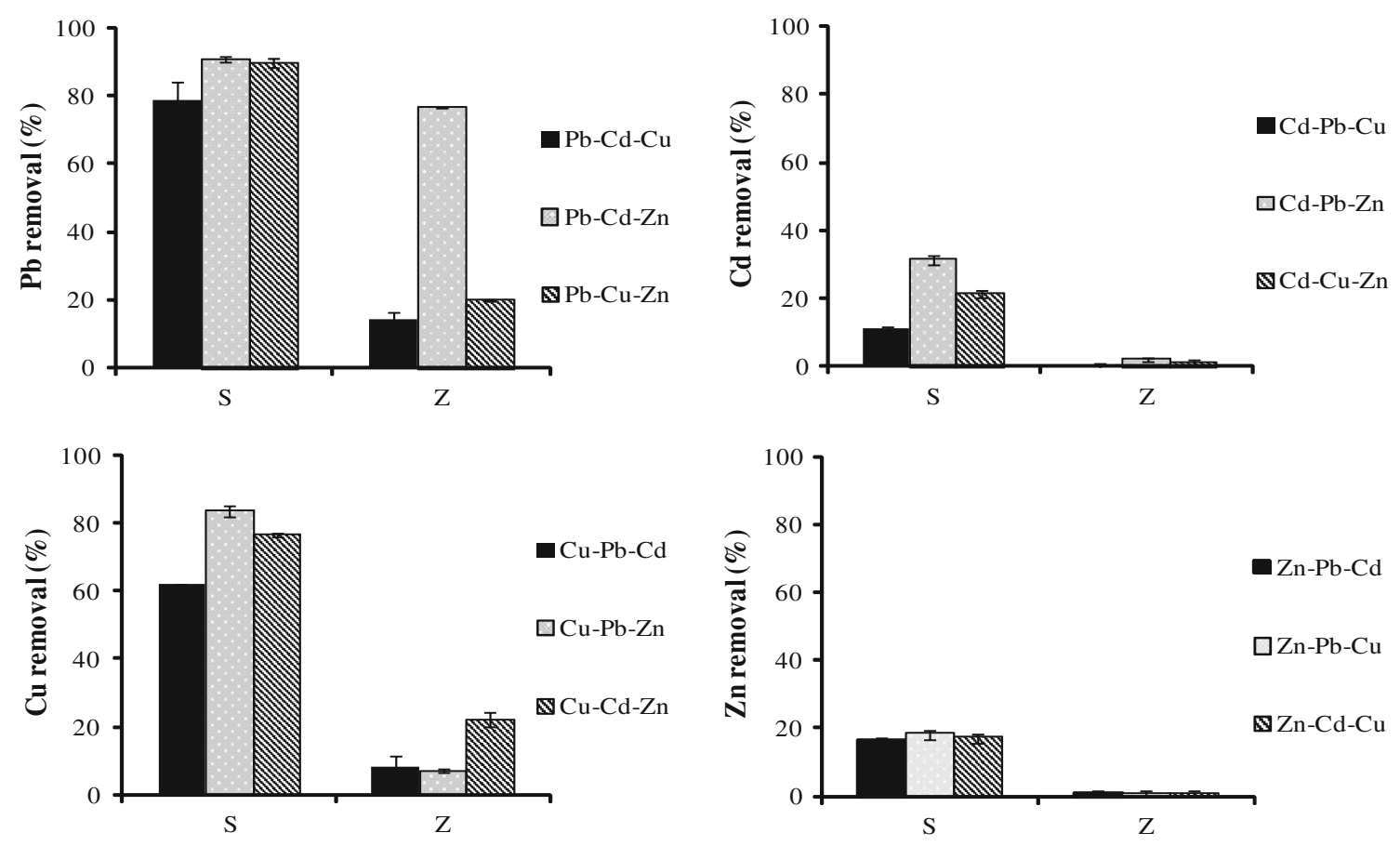

Fig. 5 Sorption of $\mathrm{Pb}, \mathrm{Cd}, \mathrm{Cu}$ and $\mathrm{Zn}$ in ternary systems

Table 4 Removal percentage of heavy metals in ternary system by natural limestone (in \%)

\begin{tabular}{llllll}
\hline Metal & Sample & $\mathrm{Pb}-\mathrm{Cd}-\mathrm{Cu}$ & $\mathrm{Pb}-\mathrm{Cd}-\mathrm{Zn}$ & $\mathrm{Pb}-\mathrm{Cu}-\mathrm{Zn}$ & $\mathrm{Cd}-\mathrm{Cu}-\mathrm{Zn}$ \\
\hline $\mathrm{Pb}$ & $\mathrm{S}$ & 78.66 & 90.75 & 89.72 & \\
& $\mathrm{Z}$ & 14.45 & 76.42 & 20.14 & \\
$\mathrm{Cd}$ & $\mathrm{S}$ & 11.11 & 31.33 & & 21.40 \\
& $\mathrm{Z}$ & 0.31 & 2.11 & & 1.23 \\
$\mathrm{Cu}$ & $\mathrm{S}$ & 62.04 & & 83.43 & 76.50 \\
& $\mathrm{Z}$ & 7.99 & & 7.23 & 22.23 \\
$\mathrm{Zn}$ & $\mathrm{S}$ & & 16.38 & 18.27 & 17.19 \\
& $\mathrm{Z}$ & & 1.13 & 0.35 & 0.57 \\
\hline
\end{tabular}

removed the following sequence $\mathrm{Pb}^{2+}>\mathrm{Cu}^{2+}>\mathrm{Cd}^{2+}$ $\approx \mathrm{Zn}^{2+}$. This indicated that the studied metals competitively interacted with limestone samples.

\section{Interaction with calcium}

Heavy metal sorption onto natural limestones started with calcium carbonate dissolution, leading to the release of calcium in the solution (Aziz et al. 2001; Alkattan et al. 2002; Sanchez and Ayuso 2002). It was clearly observed that the studied heavy metals interacted with limestone in different ways, leading to variable concentration of $\mathrm{Ca}^{2+}$ in the solution. In single-element system, more than $23 \mathrm{mg} / \mathrm{L}$ of $\mathrm{Ca}^{2+}$ was released in the solution. The presence of cadmium depressed calcite dissolution when compared to other metals (Martin-Garin et al. 2003). The concentration of released $\mathrm{Ca}^{2+}$ in the presence of cadmium was $28.04 \mathrm{mg} / \mathrm{L}$ for $\mathrm{S}$ sample and $23.74 \mathrm{mg} / \mathrm{L}$ for $\mathrm{Z}$ sample. These concentrations were the lowest when compared with the released calcium in the presence of other metals. Although it has been reported that, of the metal cations that have been studied, cadmium most easily replaces $\mathrm{Ca}^{2+}$, due to the similarity of their ionic radii (Sanchez and Ayuso 2002; Al-Degs et al. 2006), it was observed that the exchange mechanism for cadmium operates at a slow rate. It is worth noting that the presence of zinc showed the highest concentration of released $\mathrm{Ca}^{2+}$, exceeding $35.74 \mathrm{mg} / \mathrm{L}$ for the studied limestone samples. This was also verified in binary and ternary systems (Fig. 7). Inversely, the presence of cadmium decreased calcite dissolution, therefore calcium concentration. Furthermore, the inhibiting effect of cadmium was strong enough to overcome the improving effect caused by the presence of zinc. In the quadruple system, the presence of other metals strongly depressed calcium concentration because of its low electronegativity (Pauling electronegativity $=1.00$ ) compared to other metals studied, therefore its easier displacement by other competitive metals. The released calcium decreased substantially to less than 16.8 and $4.74 \mathrm{mg} / \mathrm{L}$ for $\mathrm{S}$ and $\mathrm{Z}$ samples, respectively. For each charge class, Kinraide and Yermiyahu (2007) mentioned that binding strength increased with increasing electronegativity (Table 2). It is, therefore, probable that the 

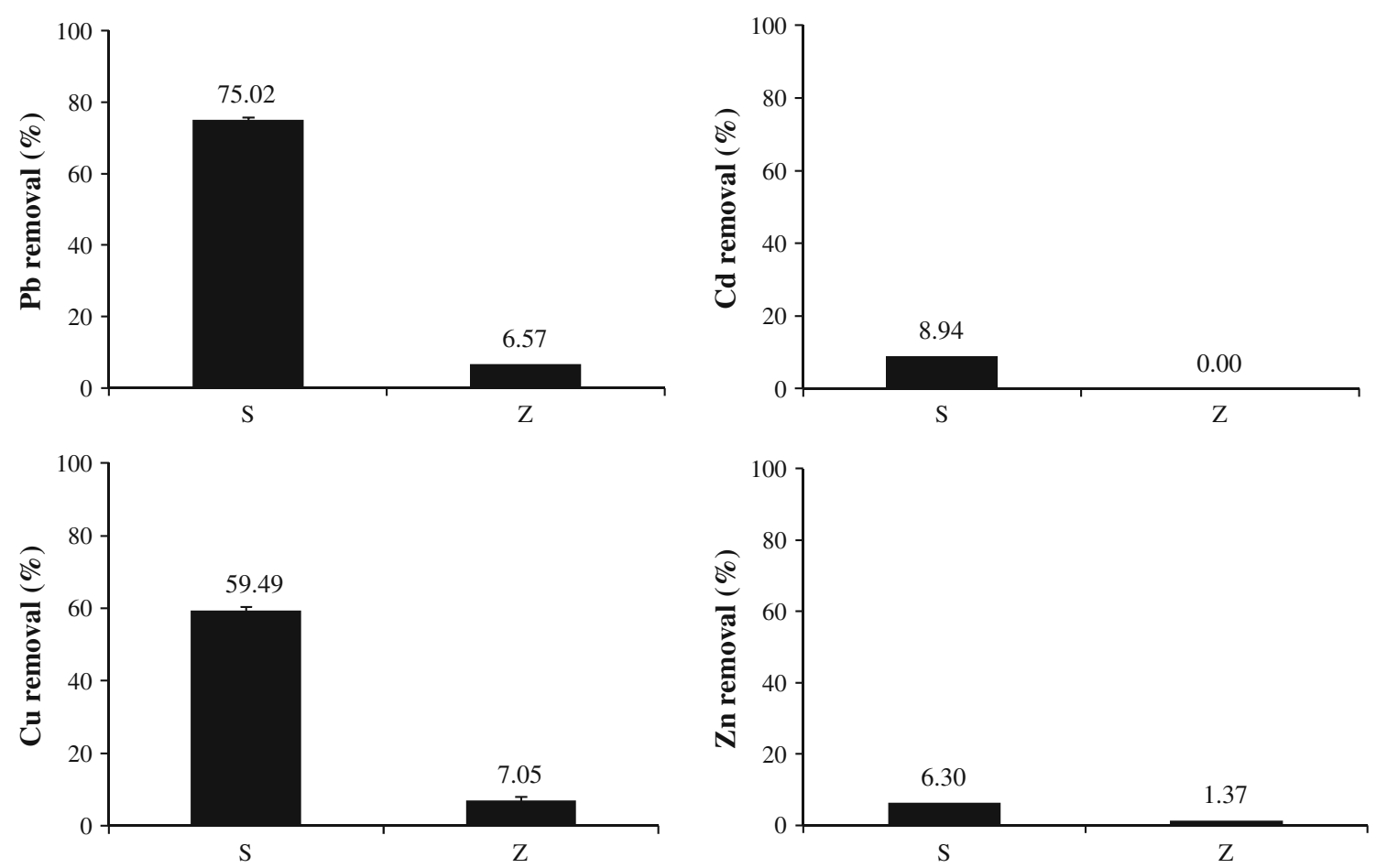

Fig. 6 Sorption of $\mathrm{Pb}, \mathrm{Cd}, \mathrm{Cu}$ and $\mathrm{Zn}$ in mixed systems
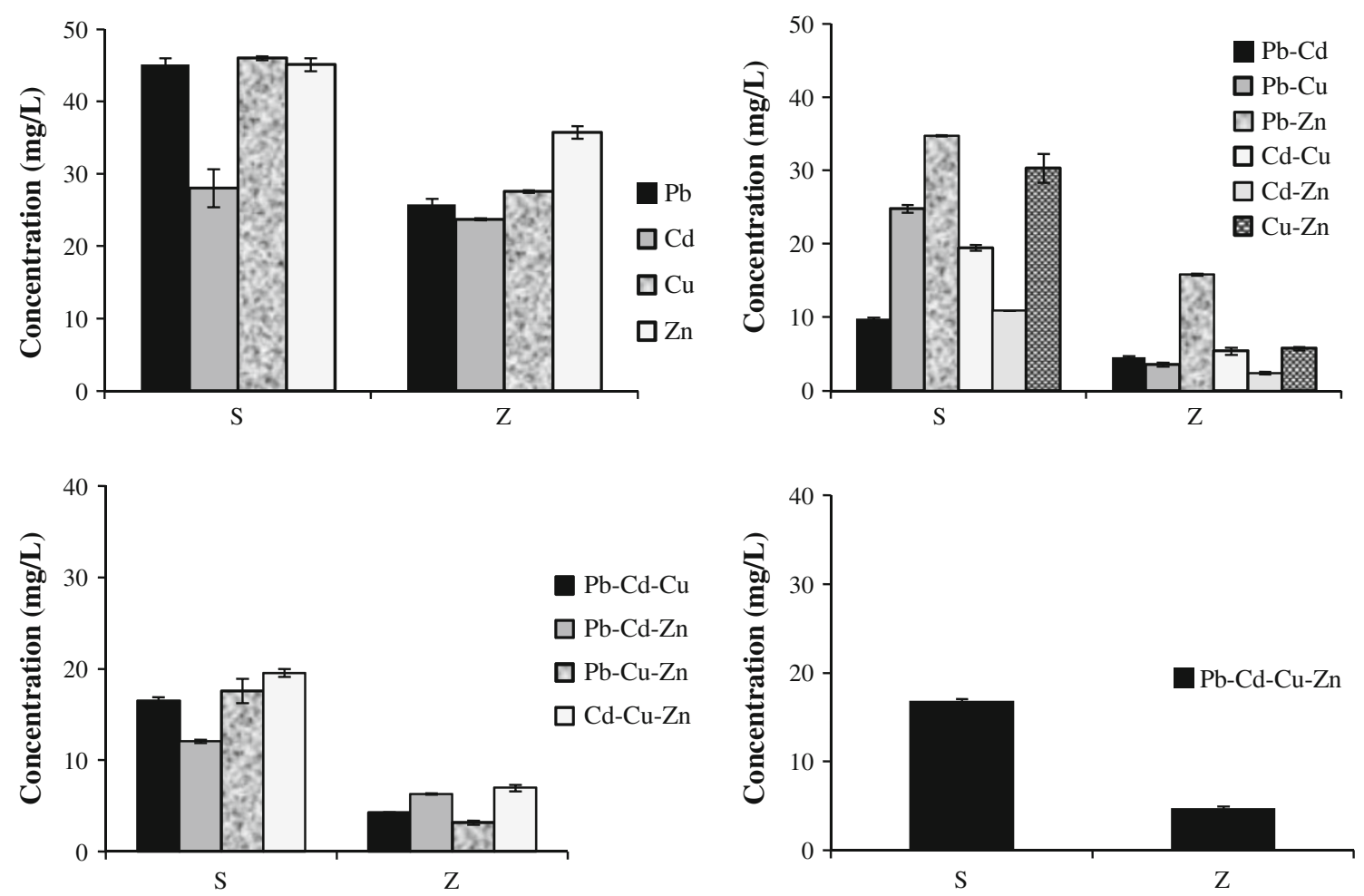

Fig. 7 Released calcium in single and multi-element systems 
differences between metal sorption capacities would depend only on their affinity to the surface of calcite.

\section{Discussion}

The removal percentages of metal cations in single and multi-element systems were compared. In single element removal, the studied limestone samples revealed higher removal efficiency than do in mixed systems. Furthermore, the limestone samples used in this study have variable chemical composition that may explain the difference in the metal adsorptive capacities. Al-Degs et al. (2006) mentioned that, based on conventional theory, metals with higher electronegativity should adsorb more readily as was the case of the studied metals. The same theory suggested that metals of higher hydrolysis constants have better adsorptive capacity (Appel et al. 2008). Moreover, differences in limestone affinity for the studied metals (i.e., $\mathrm{Pb}^{2+}, \mathrm{Cd}^{2+}, \mathrm{Cu}^{2+}$ and $\mathrm{Zn}^{2+}$ ) are mainly contingent upon those metals physico-chemical properties including electronegativity, ionic radius, hydrated radius, hydrolysis constant among others (Apiratikul and Pavasant 2006; Appel et al. 2008). This assumption can give a reasonable explanation for the higher removal of $\mathrm{Pb}^{2+}$ and $\mathrm{Cu}^{2+}$ compared to $\mathrm{Cd}^{2+}$ and $\mathrm{Zn}^{2+}$. For example, Pauling electronegativity of $\mathrm{Pb}^{2+}, \mathrm{Cu}^{2+}, \mathrm{Cd}^{2+}$ and $\mathrm{Zn}^{2+}$ are $2.33,1.90$, 1.69 and 1.65, respectively. Our experimental results showed that limestone sample's affinity followed the order $\mathrm{Pb}^{2+}>\mathrm{Cu}^{2+}>\mathrm{Cd}^{2+}>\mathrm{Zn}^{2+}$, which is consistent with the electronegativity values. Furthermore, the hydrated radius showed the sequence $\mathrm{Zn}^{2+}=4.3 \AA>\mathrm{Cd}^{2+}=$ $4.26 \AA>\mathrm{Cu}^{2+}=4.19 \AA>\mathrm{Pb}^{2+}=4.01 \AA$, indicating that smaller radius favored metal interaction with the sorbent surface (Appel et al. 2008). Numerous studies, including Godelitsas et al. (2003), Al-Degs et al. (2006) and Karageorgiou et al. (2007), reported that metals of ionic radius close to that of $\mathrm{Ca}^{2+}$ adsorb stronger. According to those works, $\mathrm{Cd}^{2+}$ should have higher sorption capacity than $\mathrm{Cu}^{2+}$ and $\mathrm{Zn}^{2+}$; however, this was not the case for the present study. In multi-element system, physical properties of metals still play an important role in the removal process. Srivastava et al. (2005) found that lead had a higher affinity than copper, which in turn had a higher affinity than cadmium and zinc. He stated that cadmium could not effectively compete with other metals because of its restricted adsorption to charge sites. Among the metal ions studied, $\mathrm{Pb}^{2+}$ was the most preferably removed cation because of its high affinity to calcite surface. Considering this observation, Pagnanelli et al. (2003) concluded that the metal with highest affinity is not significantly influenced by the presence of other heavy metals in solutions. However, the present study showed that the presence of copper strongly inhibited the removal of lead, especially in the pure limestone ( $\mathrm{Z}$ sample). As for $\mathrm{S}$ limestone sample, the presence of copper slightly decreased lead removal. This was attributed to the availability of numerous binding sites, the presence of which may render the competitive effect insignificant (Apiratikul and Pavasant 2006). It is worth noting that the presence of $\mathrm{Pb}^{2+}$ in the system more effectively decreased the sorption capacity of $\mathrm{Cu}^{2+}$ and $\mathrm{Cd}^{2+}$, but enhanced the removal of $\mathrm{Zn}^{2+}$. Therefore, these metals had only a minor competitive effect on $\mathrm{Pb}^{2+}$ adsorption and did not appear to compete with this metal for high affinity sorption sites. Both $\mathrm{Cd}^{2+}$ and $\mathrm{Zn}^{2+}$ have similar hydrated radii of 4.26 and $4.30 \AA$, respectively (Table 2), and low electronegativities than $\mathrm{Cu}^{2+}$ and $\mathrm{Pb}^{2+}$, which minimize electron sharing or covalent bond formation with the sorbent surface. Thus, coulombic interactions with surfaces were favored for $\mathrm{Zn}^{2+}$ and $\mathrm{Cd}^{2+}$. Echeverria et al. (1998) and Appel et al. (2008) reported decreased sorption of $\mathrm{Cd}^{2+}, \mathrm{Cu}^{2+}, \mathrm{Pb}^{2+}$ and $\mathrm{Zn}^{2+}$ when these metals were sorbed in mixed systems compared to single element removal. It is to be mentioned that the effect of competing ions was stronger on $\mathrm{Zn}^{2+}$ and $\mathrm{Cd}^{2+}$ removal in ternary and quadruple systems than in binary system because of the preferential sorption. Performances of natural limestones for the removal of several heavy metals from wastewaters were clearly dependent on various parameters including the physico-chemical characteristics of the limestone sample and the metal to be removed. Furthermore, the feasibility of heavy metal removal by natural limestones seemed to be related to the concentration of the metal ions, essentially. For instance, the removal of lead was the highest among the studied metals due to the high affinity to calcite surface when compared with other metals like copper, cadmium and zinc. In summary, the studied Camapanian-Maastrichian limestones of the Abiod formation, Tunisia exhibited high removal efficiency in single and multi-element systems, and therefore, was found to be suitable for removing $\mathrm{Pb}^{2+}, \mathrm{Cd}^{2+}, \mathrm{Cu}^{2+}$ and $\mathrm{Zn}^{2+}$ from aqueous solutions.

\section{Conclusions}

The present study showed that natural limestones effectively removed high percentage of heavy metals. The adsorption behavior of $\mathrm{Pb}^{2+}, \mathrm{Cd}^{2+}, \mathrm{Cu}^{2+}$ and $\mathrm{Zn}^{2+}$ onto limestones in single and mixed systems is governed by physical properties of the studied metal. The limestone from northern Tunisia, containing higher impurities such as silica and iron and aluminum oxides, showed better removal efficiency than the limestones of southern area. For all the studied metals, higher removal percentage was achieved by the low grade limestone sample from the solution of $10 \mathrm{mg} / \mathrm{L}$ in single and mixed systems. 
The selectivity sequence of the studied metal was $\mathrm{Pb}^{2+}>$ $\mathrm{Cu}^{2+}>\mathrm{Zn}^{2+} \approx \mathrm{Cd}^{2+}$ in single and mixed systems. Due to their chemical properties (high electronegativity, small hydrated radius and high hydrolysis constant), copper and lead were sorbed onto limestone surface more than cadmium and zinc. These results indicated that CampanianMaastrichtian limestones from Tunisia are expected to be promising natural resources for the removal of toxic heavy metals from wastewaters.

Open Access This article is distributed under the terms of the Creative Commons Attribution License which permits any use, distribution, and reproduction in any medium, provided the original author(s) and the source are credited.

\section{References}

Al-Degs YS, El-Barghouthi MI, Issa AA, Khraisheh MA, Walker GM (2006) Sorption of $\mathrm{Zn}(\mathrm{II}), \mathrm{Pb}(\mathrm{II})$, and $\mathrm{Co}$ (II) using natural sorbents: equilibrium and kinetic studies. Water Res 40:26452658

Alkattan M, Oelkers EH, Dandurand JL, Schott J (2002) An experimental study of calcite dissolution rates at acidic conditions and $25{ }^{\circ} \mathrm{C}$ in the presence of $\mathrm{NaPO}_{3}$ and $\mathrm{MgCl}_{2}$. Chem Geol 190:291-302

Aloui T, Chaabani F (2007) Influence of fractures and karstification on the development of a quarry at Jebel Feriana, Tunisia. Bull Eng Geol Environ 66:345-351

Apiratikul R, Pavasant P (2006) Sorption isotherm model for binary component sorption of copper, cadmium, and lead ions using dried green macroalga, Caulerpa lentillifera. Chem Eng J 119:135-145

Appel C, Ma LQ, Rhue RD, Reve W (2008) Sequential sorption of lead and cadmium in three tropical soils. Environ Pollut 155:132-140

Aziz HA, Othman N, Yusuff MS, Basri DRH, Ashaari FAH, Adlan MN et al (2001) Removal of copper from water using limestone filtration technique: determination of mechanism of removal. Environ Int 26:395-399

Aziz HA, Adlana MN, Ariffina KS (2008) Heavy metals (Cd, Pb, Zn, $\mathrm{Ni}, \mathrm{Cu}$ and $\mathrm{Cr}(\mathrm{III})$ ) removal from water in Malaysia: post treatment by high quality limestone. Bioresour Technol 99:1578-1583

Barhoumi S, Messaoudi I, Deli T, Saïd K, Kerkeni A (2009) Cadmium bioaccumulation in three benthic fish species, Salaria basilisca, Zosterisessor ophiocephalus and Solea vulgaris collected from the Gulf of Gabes in Tunisia. J Environ Sci 21:980-984

Bouaziz S, Sghari A, Benzina M, Sdiri A, Chaabouni R (2007) Les matières premières naturelles du gouvernorat de Gabes: caractérisation et utilisations. ODS, Tunisia

Cave K, Talens-Alesson FI (2005) Comparative effect of Mn(II) and $\mathrm{Fe}$ (III) as activators and inhibitors of the adsorption of other heavy metals on calcite. Colloids Surf A 268:19-23

Cubillas P, Köhler S, Prieto M, Causserand C, Oelkers EH (2005) How do mineral coatings affect dissolution rates? An experimental study of coupled $\mathrm{CaCO}_{3}$ dissolution- $-\mathrm{CdCO}_{3}$ precipitation. Geochim Cosmochim Acta 69:5459-5476

Davis AD, Dixon DJ, Sorensen LJ (2006) Development of an agglomeration process to increase the efficiency of limestonebased material to remove metals from drinking water. South Dakota
Echeverria JC, Morera MT, Mazkiaran C, Garrido JJ (1998) Competitive sorption of heavy metal by soils. Isotherms and fractional factorial experiments. Environ Pollut 101:275-284

Eloussaief M, Benzina M (2010) Efficiency of natural and acidactivated clays in the removal of $\mathrm{Pb}$ (II) from aqueous solutions. J Hazard Mater 178:753-757

Eloussaief M, Kallel N, Yaacoubi A, Benzina M (2011) Mineralogical identification, spectroscopic characterization, and potential environmental use of natural clay materials on chromate removal from aqueous solutions. Chem Eng J 168:1024-1031

Eloussaief M, Hamza W, Kallel N, Benzina M (2012) Wastewaters decontamination: Mechanisms of $\mathrm{Pb}(\mathrm{II}), \mathrm{Zn}(\mathrm{II})$, and $\mathrm{Cd}(\mathrm{II})$ competitive adsorption on tunisian smectite in single and multisolute systems. Environ Prog Sustainable Energy. doi:10.1002/ ep.11609

Godelitsas A, Astilleros JM, Hallam K, Harissopoulos S, Putnis A (2003) Interaction of calcium carbonates with lead in aqueous solutions. Environ Sci Technol 37:3351-3360

Karageorgiou K, Paschalis M, Anastassakis GN (2007) Removal of phosphate species from solution by adsorption onto calcite used as natural adsorbent. J Hazard Mater 139:447-452

Kinraide TB, Yermiyahu U (2007) A scale of metal ion binding strengths correlating with ionic charge, Pauling electronegativity, toxicity, and other physiological effects. J Inorg Biochem 101:1201-1213

Komnitsas K, Bartzas G, Paspaliaris I (2004) Efficiency of limestone and red mud barriers: laboratory column studies. Miner Eng 17:183-194

Martin-Garin A, Van Cappellen P, Charlet L (2003) Aqueous cadmium uptake by calcite: a stirred flow-through reactor study. Geochim Cosmochim Acta 69:2763-2774

Martins RJ, Pardo R, Boaventura RA (2004) Cadmium(II) and zinc(II) adsorption by the aquatic moss Fontinalis antipyretica: effect of temperature, $\mathrm{pH}$ and water hardness. Water Res 38:693-699

Messaoudi I, Barhoumi S, Saïd K, Kerkeni A (2009) Study on the sensitivity to cadmium of marine fish Salaria basilisca (Pisces: Blennidae). J Environ Sci 21:1620-1624

Pagnanelli F, Esposito A, Toro L, Veglio F (2003) Metal speciation and $\mathrm{pH}$ effect on $\mathrm{Pb}, \mathrm{Cu}, \mathrm{Zn}$ and $\mathrm{Cd}$ biosorption onto Sphaerotilus natans: Langmuir-type empirical model. Water Res 37:627-633

Pickering WF (1983) Extraction of copper, lead, zinc or cadmium ions sorbed on calcium carbonate. Water Air Soil Pollut 20:299-309

Prieto M, Cubillas P, Gonzalez FA (2003) Uptake of dissolved Cd by biogenic and abiogenic aragonite: a comparison with sorption onto calcite. Geochim Cosmochim Acta 67:3859-3869

Rouff AA, Elzinga EJ, Reeder RJ, Fisher NS (2006) The Effect of aging and $\mathrm{pH}$ on $\mathrm{Pb}(\mathrm{II})$ sorption processes at the calcite-water interface. Environ Sci Technol 40:1792-1798

Sanchez AG, Ayuso EA (2002) Sorption of Zn, Cd and Cr on calcite. Application to purification of industrial wastewaters. Miner Eng 15:539-547

Sdiri A, Higashi T, Hatta T, Jamoussi F, Tase N (2010) Mineralogical and spectroscopic characterization, and potential environmental use of limestone from the Abiod formation, Tunisia. Environ Earth Sci 61:1275-1287

Sdiri A, Higashi T, Hatta T, Jamousssi F, Tase N (2011) Evaluating the adsorptive capacity of montmorillonitic and calcareous clays on the removal of several heavy metals in aqueous systems. Chem Eng J 172:37-46

Sdiri A, Higashi T, Chaabouni R, Jamousssi F (2012a) Competitive removal of heavy metals from aqueous solutions by montmorillonitic and calcareous clays. Water Air Soil Pollut 223:11911204 
Sdiri A, Higashi T, Jamousssi F, Bouaziz S (2012b) Effects of impurities on the removal of heavy metals by natural limestones in aqueous systems. J Environ Manag 93:245-253

Srivastava P, Singh B, Angove M (2005) Competitive adsorption behavior of heavy metals on kaolinite. J Colloid Interface Sci 290:28-38

Xue Y, Hou H, Zhu S (2009) Competitive adsorption of copper(II), cadmium(II), lead(II) and zinc(II) onto basic oxygen furnace slag. J Hazard Mater 162:391-401
Zhu J, Pigna M, Cozzolino V, Caporale AG, Violante A (2010) Competitive sorption of copper(II), chromium(III) and lead(II) on ferrihydrite and two organomineral complexes. Geoderma 159:409-416 